\title{
Review
}

\section{It is complicated: Potential short- and long-term impact of coronavirus disease 2019 (COVID-19) on antimicrobial resistance-An expert review}

\author{
Marco Seneghini $M D^{1}$ (1), Susanne Rüfenacht $M^{1}$, Baharak Babouee-Flury $\mathrm{MD}^{1,2}$, Domenica Flury $\mathrm{MD}^{1}$ (1), \\ Matthias Schlegel MD ${ }^{1}$, Stefan P. Kuster MD, MSc ${ }^{1}$ (D) and Philipp P. Kohler MD, MSc (D) \\ ${ }^{1}$ Division of Infectious Diseases and Hospital Epidemiology, Cantonal Hospital St Gallen, St Gallen, Switzerland and ${ }^{2}$ Medical Research Centre, Cantonal Hospital \\ St Gallen, St Gallen, Switzerland
}

\begin{abstract}
As of December 2021, the coronavirus disease 2019 (COVID-19) pandemic has claimed millions of deaths and caused disruptions in health systems around the world. The short- and long-term effects of COVID-19 on antimicrobial resistance (AMR), which was already a global threat before the pandemic, are manifold and complex. In this expert review, we summarize how COVID-19 might be affecting AMR in the short term (by influencing the key determinants antibiotic use, infection control practices and international/local mobility) and which additional factors might play a role in the long term. Whereas reduced outpatient antibiotic use in high-income countries, increased awareness for hand hygiene, and reduced mobility have likely mitigated the emergence and spread of AMR in the short term, factors such as overuse of antibiotics in COVID-19 patients, shortage of personal protective equipment, lack of qualified healthcare staff, and patient overcrowding have presumably facilitated its propagation. Unsurprisingly, international and national AMR surveillance data for 2020 show ambiguous trends. Although disruptions in antibiotic stewardship programs, AMR surveillance and research might promote the spread of AMR, other developments could prove beneficial to the cause in the long term. These factors include the increased public awareness for infectious diseases and infection control issues, the strengthening of the One Health perspective as outlined by the Centers for Disease Control and Prevention, and the unprecedented number of international research collaborations and platforms. These factors could even serve as leverage and provide opportunities to better combat AMR in the future.
\end{abstract}

(Received 28 December 2021; accepted 28 December 2021)

As of December 2021, the coronavirus disease 2019 (COVID-19) pandemic has affected $>270$ million people and has claimed $>5$ million lives worldwide. ${ }^{1}$ Consequently, healthcare systems around the globe are confronted with hitherto unmet challenges due to high COVID-19 patient numbers, lack of resources, and disruption of routine processes. Similar to COVID-19, antimicrobial resistance (AMR) represents a global public health threat that has been termed "the slow pandemic" to emphasize its more insidious increase. $^{2}$ Infections due to resistant pathogens result in $\sim 700,000$ deaths annually. This number has been estimated to increase to 10 million deaths annually by the year $2050 .^{3}$

Experts have warned about the potentially deleterious effects of the COVID-19 pandemic on AMR due to the deprioritization of infection prevention and control (IPC) and antimicrobial stewardship programs (ASPs). ${ }^{4}$ On the other hand, factors such as social

Author for correspondence: Philipp P. Kohler, MD, MSc, Division of Infectious Diseases and Hospital Epidemiology, Cantonal Hospital St Gallen, St Gallen, Switzerland. E-mail: philipp.kohler@kssg.ch

Cite this article: Seneghini M, et al. (2022). It is complicated: Potential short- and longterm impact of coronavirus disease 2019 (COVID-19) on antimicrobial resistance-An expert review. Antimicrobial Stewardship \& Healthcare Epidemiology, https://doi.org/ 10.1017/ash.2022.10 distancing and reduced international travel could potentially have favorable effects on limiting AMR prevalence. ${ }^{5,6}$ We compiled the available evidence on the potentially harmful but also beneficial effects of the COVID-19 pandemic on 3 key determinants of AMR: antibiotic use, IPC measures, and international mobility. We also summarize the net effect that these changes have had on AMR in the short term by compiling national and international AMR surveillance data from 2020. Finally, we discuss how the COVID-19 pandemic could affect AMR in the long term, considering potential amplifying and moderating factors.

\section{Antibiotic use during the COVID-19 pandemic}

The main mechanisms for the development and spread of AMR are antibiotic-induced mutagenesis and selection pressure. ${ }^{7}$ The association between antibiotic use and the emergence of AMR has been well established, both from before and during the pandemic., ${ }^{8,9}$

For the inpatient setting, data on antibiotic consumption are most often expressed as defined daily doses (DDD) per number of bed days or patient days. Changes in this measure do not necessarily reflect changes in the overall antibiotic consumption if absolute patient numbers have also changed. For example, data from the Veterans' Health Administration show an increase in

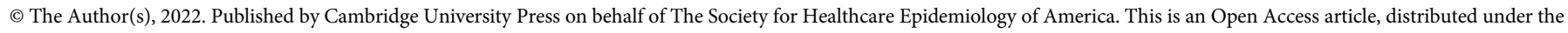
terms of the Creative Commons Attribution licence (http://creativecommons.org/licenses/by/4.0/), which permits unrestricted re-use, distribution and reproduction, provided the original article is properly cited. 


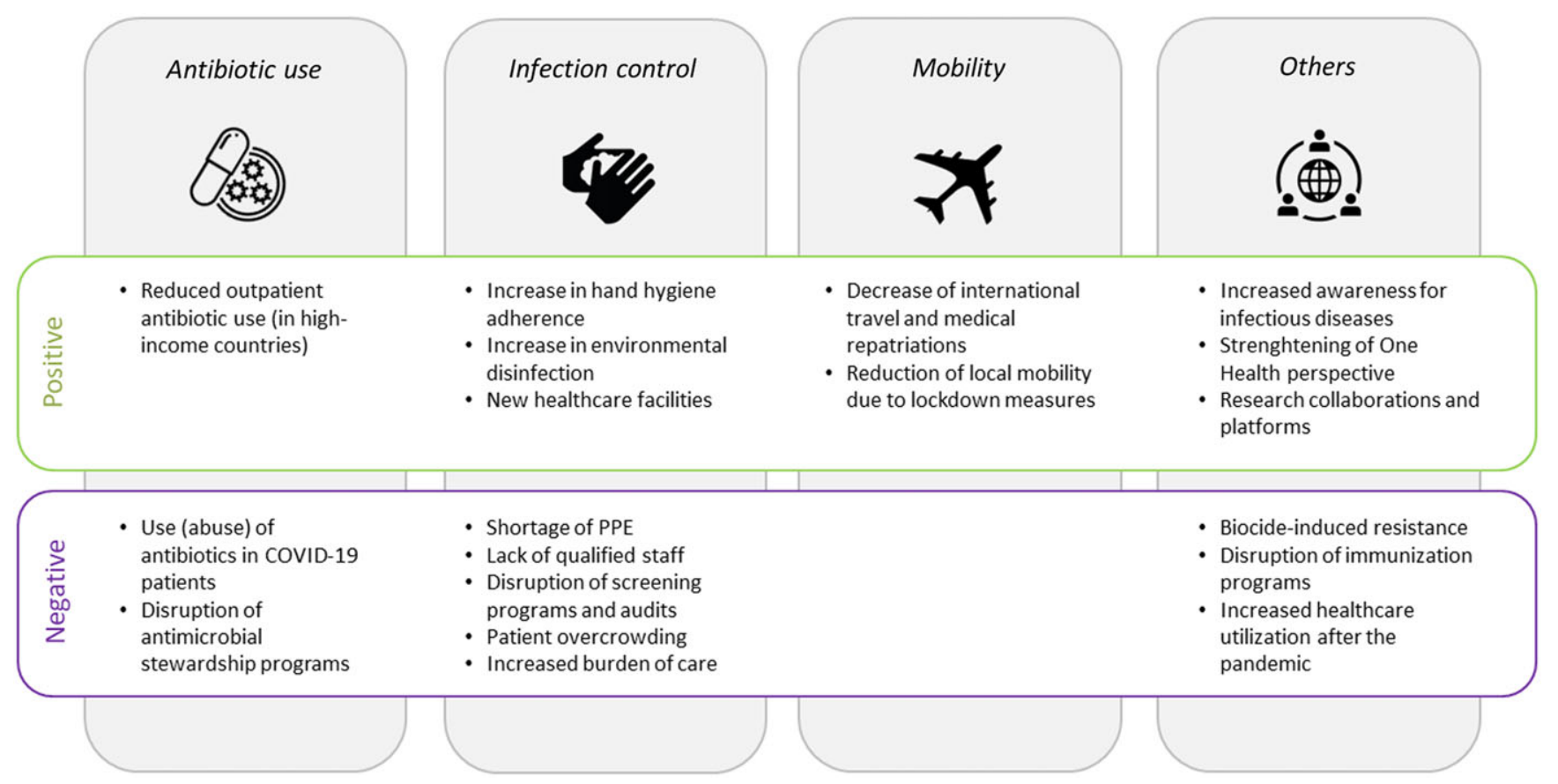

Fig. 1. Factors associated with an increase (positive) or a decrease (negative) in antimicrobial resistance. Note. PPE, personal protective equipment.

the density of antimicrobial utilization (ie, antibiotic use per 1,000 patient days) in the inpatient setting for the year 2020, whereas overall antibiotic use decreased, probably due to decreases in healthcare utilization related to non-COVID-19 conditions. ${ }^{10}$ Similarly, national surveillance data from the United Kingdom show that total consumption (calculated as DDD per 1,000 inhabitants per day) decreased by $11 \%$ between 2019 and 2020.11 However, when looking at DDD per 1,000 admissions, antibiotic consumption for inpatients increased by almost $5 \%$, reflecting changes in hospital populations since the start of the pandemic. ${ }^{11}$ Indeed, as many as $72 \%$ of COVID-19 patients receive antibiotic treatment, either on an empirical basis or to treat a confirmed bacterial coinfection, although bacterial coinfections are observed in only $15 \%-25 \% .^{12,13}$ Many of these superinfections are due to hospital-acquired infections, mostly ventilator-associated pneumonia and central-line-associated bloodstream infections. ${ }^{14}$ In line with these observations, antibiotic use in 17 hospitals in South Carolina increased in those institutions admitting COVID-19 patients but not in those not treating COVID-19 patients. Notably, this increase was mostly due to broad-spectrum and anti-methicillin-resistant Staphylococcus aureus agents. ${ }^{15}$ The use of antifungal substances, which has massively increased in the inpatient and particularly the ICU setting during the pandemic, ${ }^{11,16}$ is an important topic that is beyond the scope of this review.

For the community setting, several high-income countries (HICs) have reported reductions in antibiotic consumption in 2020. In the United States, antibiotic consumption decreased by $33 \%,{ }^{17}$ in Canada it decreased by $26 \%,{ }^{18}$ and in countries of the European Union it decreased by $18 \% .{ }^{19}$ These effects have been mostly attributed to decreased consumption of antibiotics commonly used to treat children and to treat respiratory infections. ${ }^{11,17-19}$ This trend likely reflects the reduction in non-COVID-19 respiratory diseases that has been reported from around the globe during the pandemic, probably owing to social distancing and community lockdowns. For instance, seasonal influenza activity in 2020 was minimal in Brazil, ${ }^{20}$ Singapore, ${ }^{21}$ Japan, ${ }^{22}$ Taiwan, ${ }^{23}$ and Europe. ${ }^{24}$ In Australia, an impressive decrease in respiratory syncytial virus infections among children has been described. ${ }^{25}$ Not only viral but also bacterial pathogens with the respiratory route as primary transmission pathway have decreased substantially. Surveillance data from 26 countries have shown a sustained reduction in invasive diseases due to Streptococcus pneumoniae, Haemophilus influenzae, and Neisseria meningitides. ${ }^{26}$

Despite these favorable trends from the community setting observed in HICs, opposite trends have been reported from India, where a significant increase in nonpediatric antibiotic sales (mainly azithromycin) was observed during the first COVID-19 epidemic wave. Similar trends may have occurred in other lowand middle-income countries (LMICs), ${ }^{27}$ where antibiotics are commonly dispensed over the counter without a prescription. ${ }^{28,29}$

In sum, although COVID-19 patients are often (unnecessarily) treated with antibiotic substances, overall antibiotic consumptionparticularly in the community setting - has decreased during the pandemic according to several national and international surveillance reports (Fig. 1). This is mainly true for HICs, whereas data from LMICs are either lacking or show increases in use.

\section{Infection prevention and control}

Infection prevention and control (IPC) measures are essential in controlling the spread of both COVID-19 and AMR. The contagiousness of severe acute respiratory coronavirus virus 2 (SARS$\mathrm{CoV}-2$ ) and the unprecedented enormous strain on hospitals have led to fundamental changes in IPC measures that have unavoidably affected the spread of multidrug-resistant organisms (MDRO) in hospitals. According to an international survey of the Global Antimicrobial Resistance and Use Surveillance System (GLASS), the quality of many IPC measures improved in several countries during the pandemic. IPC training of healthcare workers 
(HCWs) has been reinforced, use of personal protective equipment (PPE) was expanded, and adherence to hand hygiene ( $\mathrm{HH})$ has improved (Fig. 1). ${ }^{30}$ In a meta-analysis, $\mathrm{HH}$ adherence during COVID-19 was $74 \%$, which was higher than generally estimated. ${ }^{31}$ For example, $\mathrm{HH}$ adherence increased from $46 \%$ before the pandemic to $89 \%$ during the pandemic in a study from Israel. ${ }^{32}$ Similarly, a study from Chicago analyzing data from automated $\mathrm{HH}$ monitoring revealed an increase in adherence from $55 \%$ at baseline to $76 \%$ during the pandemic. ${ }^{33}$ Achieved improvement, however, concomitantly decreased with decreasing SARS-CoV-2 infection rates. ${ }^{33-35}$ Interestingly, $\mathrm{HH}$ adherence has previously been described to increase during seasonal or pandemic influenza periods and could be due to increased awareness or selfprotection. ${ }^{36,37}$

Furthermore, environmental disinfection has intensified in many places, which might also have had the benefit of eliminating unnoticed environmental MDRO sources. ${ }^{38,39}$ To contain an everincreasing number of COVID-19 patients and anticipating surges, hospital admissions for non-COVID-19 patients decreased, potentially resulting in a lower number of transmissions from chronic MDRO carriers. ${ }^{40}$ An additional strategy adopted by many countries to increase overall patient capacity was to create "ad hoc" COVID-19 facilities or even new hospitals in record time. ${ }^{41-43}$ Such measures at least partly mitigated hospital overcrowding, which is a clear risk for cross transmission. ${ }^{44}$

On the other hand, breaches in adherence to standard IPC practices were also reported in the GLASS survey. ${ }^{30}$ Indeed, MDRO outbreaks have frequently been reported from COVID-19 wards. Particularly common were upsurges of Candida auris and carbapenem-resistant organisms (CROs), which could be at least partly ascribed to decreased adherence to IPC practices. ${ }^{45-58}$ A formative research study from 2020 underlined stress and busyness as potential barriers to correct $\mathrm{HH}$ performance. ${ }^{59}$ Similarly, longer duty hours and suboptimal $\mathrm{HH}$ were associated with SARS-CoV-2 acquisition among HCWs. ${ }^{60} \mathrm{PPE}$ shields HCWs from infection, and gloving hands paradoxically can reduce $\mathrm{HH}$ compliance, ${ }^{61,62}$ which has been revealed during the ongoing pandemic. ${ }^{35}$ For instance, in a carbapenem-resistant Enterobacterales (CRE) outbreak report from an Italian ICU, COVID-19 patients needing ventilation in the prone position were more likely to acquire CRE. Furthermore, contamination of gloves and gowns of HCW involved in patient positioning might have contributed to CRE transmission. ${ }^{63}$

Another factor often mentioned in the context of MDRO outbreaks is PPE shortages, which have affected both HICs and LMICs. ${ }^{64-66}$ In addition, lack of supllies might have led in some cases to the practice of sharing or reusing PPE, which also increases the risk of cross transmission. ${ }^{67}$ An additional factor contributing to disruption in IPC measures is the shortage of healthcare staff. Reasons for staff shortages are (1) HCW s on sick leave, as frontline HCWs have at least a 3 -fold increased risk of acquiring SARSCoV-2 compared to the general community ${ }^{68}$; (2) sick leave due to conditions other than COVID-19, for instance, due to burnout or other mental illnesses which have frequently been reported among HCW during the pandemic ${ }^{69}$; (3) HCWs in quarantine as a consequence of SARS-CoV-2 positive household contacts; and (4) a relative shortage due to increased need of care for COVID-19 patients. $^{70}$ Indeed, a critically low HCW-to-patient ratio is a well-established risk factor for the transmission of MDROs, as shown for MRSA. ${ }^{71}$ Also, newly recruited staff without work experience in ICU settings and without the necessary competences in IPC practices have been mentioned as factor contributing to MDRO outbreaks. ${ }^{63}$ Other collateral damage of the pandemic that has negatively affected AMR includes the suspension of routine PPE- and hand hygiene audits and the interruption of MDRO admission screening programs (Fig. 1). ${ }^{58,72}$

\section{Mobility and travel restrictions}

The spread of MDROs is highly facilitated by international and local travel. Travelers to LMICs with high AMR prevalence are at particular risk to become colonized with resistant, mostly gram-negative bacteria. ${ }^{73,74}$ For instance, up to $80 \%$ of travelers to South Asia are at least transiently colonized with ESBL-producing Enterobacterales. ${ }^{75,76}$ Once colonized, $>10 \%$ remain colonized for 12 months, and $12 \%$ will transmit the pathogen to another household member. ${ }^{76}$ The role of leisure tourism in the spread of MDROs is still likely to be underestimated because returning travelers are not routinely tested for resistant bacteria unless they exhibit symptoms. ${ }^{77}$ Travelers with healthcare contact abroad are at a high risk to be colonized or infected with even more resistant pathogens, including carbapenem-producing organisms. ${ }^{78,79}$ Also, patients undergoing aeromedical evacuation have a higher risk of being colonized with methicillin-resistant S. aureus (MRSA) or multidrug-resistant gram-negative bacilli. ${ }^{80}$ Aeromedical evacuations of such patients from countries with a high burden of AMR have resulted in many nosocomial outbreaks in low-endemicity countries. ${ }^{81-83}$

Many countries started to impose travel bans and quarantine restrictions due to COVID-19, and a large decrease in international air travel was predicted for $2020 .^{84}$ Similarly, as a consequence of the travel restrictions, a decrease of $44 \%$ in medical repatriations in the year 2020 were predicted in Switzerland according to the annual report of the Swiss Air-Rescue. ${ }^{85}$ As a result of such a reduction in normal travel patterns and medical repatriations, a decrease in the prevalence of carriage with mainly ESBL-producing Enterobacterales and lower importation of high-risk pathogens into low-endemicity countries is likely. ${ }^{86}$

Lockdown measures during COVID-19 affected not only international travel but also local mobility. According to Google mobility reports, a reduction in human movement, along with mitigation of SARS-CoV-2 spread, occurred in $2020 .{ }^{87,88}$ Although the role of local mobility for the acquisition of resistant pathogens is unclear, the reduction of human contacts accompanying reduced mobility might decrease the spread of some pathogens. At least for MRSA, detection in public transportation and other public spaces has been reported, which could definitely point toward a lower risk of MDRO acquisition with decreased local mobility. ${ }^{89-93}$

In sum, decreased international travel and local mobility can be expected to reduce the burden of AMR (Fig. 1). This trend might be particularly true for low-endemicity countries, where importation of resistant pathogens is a relevant contributor to the local burden of AMR. However, the positive impact of such measures will most likely subside as soon as mobility restrictions are lifted and international travel has returned to prepandemic levels.

\section{Net effect on AMR in 2020}

Surveillance data from Europe for 2020 suggest that the COVID-19 pandemic has affected AMR in many ways. ${ }^{94}$ In countries of the European Union, most bacterial species-antimicrobial group combinations show a decreasing or stabilizing trend in 2020 including third-generation cephalosporin-resistant Escherichia coli. $^{94}$ Similarly, data from the United Kingdom show that the burden of antibiotic resistance declined in 2020, largely due to a decrease 
in E. coli bloodstream infections. ${ }^{11}$ These trends could indeed be explained by the massive reduction of international travel, which is associated with acquisition of ESBL Enterobacterales.

Whereas community-acquired pathogens, such as E. coli or S. pneumoniae, have been less frequently reported in 2020, typical healthcare pathogens, such as Acinetobacter spp or Enterococcus faecium, were more frequently observed, according to data from the Central Asian and European Surveillance of Antimicrobial Resistance (CAESAR) network. Similar results have been reported from the European Antimicrobial Resistance Surveillance Network (EARS-Net). ${ }^{94}$ Also, alerts have been issued on the emergence of CPE from Latin America and the Caribbean region. ${ }^{95}$ Contrasting with these trends, the number of CPE isolates decreased in Switzerland in $2020 .{ }^{96}$ Factors that could explain these discrepancies between countries include the local endemicity of specific resistant pathogens and the different strain on healthcare systems caused by COVID-19.

As with antibiotic consumption data, AMR surveillance data must be interpreted with careful consideration of the denominator. ${ }^{97}$ Also, screening for high-risk pathogens, such as CPE or VRE, stopped in certain low-risk settings. ${ }^{11}$ Furthermore, resources for AMR surveillance programs have been shortened or reassigned to other areas during the pandemic, as reported by most of the 73 countries participating in the GLASS survey. Particularly in LMICs, reduced availability of laboratory reagents to detect resistant pathogens has been reported. ${ }^{30}$

\section{Long-term impact of COVID-19 on AMR}

How the COVID-19 pandemic might affect AMR in the long term remains unclear. ${ }^{98}$ The pandemic might facilitate further propagation of AMR, although many unintended consequences might also help to mitigate AMR (Fig. 1). Early in the pandemic, experts warned that disruption of antimicrobial stewardship during the pandemic could result in further expansion of AMR. ${ }^{99}$ Indeed, in a before-and-after study from Naples, Italy, antibiotic consumption increased after the interruption of an ASP, mainly in surgical wards and in wards where the ASP was less established. ${ }^{100}$ To prevent such effects, integration of antimicrobial stewardship specialists into disaster preparedness plans has been advocated, ${ }^{72}$ and suggestions have been made regarding how antimicrobial stewardship activities could be refocused in the light of the COVID-19 pandemic. ${ }^{101}$ In fact, several hospitals have reported successful adaptation of their ASP to the COVID-19 response. ${ }^{102,103}$ How these interruptions and modifications of ASP affect antibiotic consumption and how this impacts on AMR in the long term remains to be seen.

Elective surgeries and chemotherapies for cancer patients had to be delayed during the pandemic. ${ }^{104-106}$ These delays have potentially contributed to a reduced healthcare utilization and also to reductions in antibiotic prescribing. Due to the accumulated demand for these interventions in the near future, a rebound effect is likely in the sense that these interventions will add pressure to healthcare systems and will eventually increase antimicrobial use anew. ${ }^{107}$ Again, the availability of institutional ASPs will be critical to controlling this scenario.

Another aspect of the pandemic is the massive increase in the use of biocides, defined as compounds with antiseptic, disinfectant, or even preservative capacities ${ }^{108}$ in both community and hospital settings. ${ }^{109,110}$ Questions regarding their possible impact on AMR, including cross resistance to unrelated antimicrobials, have been raised. ${ }^{111}$ Biocides can lead to AMR in many ways: membrane modification, upregulation of efflux pumps, ${ }^{112}$ the increase of the propensity to form biofilms, ${ }^{113}$ or even the induction of a viable but nonculturable state that permits survival in unfavorable environmental conditions. ${ }^{114}$

However, due to insufficient investigative data and lack of standardized protocols, the full magnitude of the possible impact of biocides on AMR in the long term remains difficult to assess. ${ }^{113}$ In general, the One Health aspect outlined by the Centers for Disease Control and Prevention has gained considerable attention during the pandemic. The origin of SARS-CoV-2 is suspected to have occurred at the interface among humans, animals, and the environment. ${ }^{115}$ Several factors facilitating the spread of SARS-CoV-2 have been discussed such as climate change, growing populations, mobility, and global trade. International initiatives have been launched to address these issues and to be prepare for emerging zoonotic diseases. ${ }^{116}$ Strengthening the One Health perspective will most likely have a positive impact on limiting AMR in the long term. ${ }^{117}$

From a global health perspective, the disruption of immunization programs-especially in LMICs-harbors the risk for major long-term consequences. Data from Pakistan and Saudi Arabia show that routine immunization of children was considerably impaired in 2020, making this vulnerable population susceptible to diseases that may require antibiotic treatment. ${ }^{118,119}$ Notably, US national authorities also reported a decline in routine pediatric vaccine ordering early in the pandemic. ${ }^{120,121}$

The COVID-19 pandemic has revolutionized our idea of international collaborations and data exchange, particularly regarding genomic surveillance. ${ }^{122}$ A multitude of international research groups have been established to study the epidemiology, risk factors and therapeutic aspects of COVID-19. ${ }^{123}$ These newly created infrastructures and platforms provide excellent research opportunities to study and tackle other infectious diseases including drug-resistant pathogens. ${ }^{124,125}$

On the societal level, awareness and sensitization regarding infectious diseases and IPC has been boosted by the COVID-19 pandemic. $^{124}$ This awareness could reinforce the role of these disciplines within hospitals and healthcare systems, increase chances for research funding, and facilitate support from public health authorities.

An important limitation of this review is the lack of data from LMICs, where the consequences of COVID-19 on AMR might be even more pronounced due to preexisting inequalities, including weak or nonexisting antibiotic regulations, insufficient infrastructure, technological gaps, and inadequate health coverage. ${ }^{126}$ Therefore, a better understanding of the inter-relatedness of COVID-19 and AMR might be of particular importance for LMICs.

In conclusion, the ways in which the COVID-19 pandemic has affected and will influence AMR are manifold. For the hospital setting, high antibiotic consumption in COVID-19 patients and several MDRO outbreaks during the pandemic have been reported; however, national AMR surveillance data show ambiguous trends. For the community setting, surveillance data show decreases in antibiotic consumption and in AMR for the year 2020, at least for HICs. Differences between countries with prepandemic low and high AMR burdens and limitations arising from the disruption of AMR surveillance programs (particularly in LMICs) have to be considered when interpreting these findings. The long-term impact of the pandemic on AMR remains unclear. However, the increased public awareness for infectious diseases and for One Health issues in the wake of the pandemic, and the unprecedented intensity of international research networks and collaborations can provide leverage and opportunities to better combat AMR in the near future. 


\section{Acknowledgments. None.}

Financial support. P.K. is funded by the Swiss National Science Foundation (Ambizione grant no. PZ00P3_179919).

Conflicts of interest. All authors report no conflicts of interest relevant to this article.

\section{References}

1. COVID live update: $252,253,520$ cases and 5,091,111 deaths from the coronavirus. Worldometer website. https:/www.worldometers.info/ coronavirus/. Updated daily. Accessed 2021.

2. Spotlight on antimicrobial resistance: the slow pandemic. Royal Society of Medicine website. https://www.rsm.ac.uk/events/rsm-studios/2021-22/ ceq03/. Accessed February 3, 2022.

3. O'Neil J. Antimicrobial resistance: tackling a crisis for the health and wealth of nations - the review on antimicrobial resistance chaired by. Wellcome website. https://wellcomecollection.org/works/rdpck35v. Accessed February 3, 2022.

4. Clancy CJ, Buehrle DJ, Nguyen MH. PRO: the COVID-19 pandemic will result in increased antimicrobial resistance rates. J Antimicrob Resist 2020;2(3):dlaa049.

5. Collignon P, Beggs JJ. CON: COVID-19 will not result in increased antimicrobial resistance prevalence. J Antimicrob Resist 2020;2(3):dlaa051.

6. Monnet DL, Harbarth S. Will coronavirus disease (COVID-19) have an impact on antimicrobial resistance? Euro Surveill 2020;25:2001886.

7. Revitt-Mills SA, Robinson A. Antibiotic-induced mutagenesis: under the microscope. Front Microbiol 2020;11:585175.

8. Bork JT, Leekha S, Claeys K, et al. Change in hospital antibiotic use and acquisition of multidrug-resistant gram-negative organisms after the onset of coronavirus disease 2019. Infect Control Hosp Epidemiol 2021;42:1115-1117.

9. Yang P, Chen Y, Jiang S, Shen P, Lu X, Xiao Y. Association between antibiotic consumption and the rate of carbapenem-resistant gram-negative bacteria from China based on 153 tertiary hospitals data in 2014 . Antimicrob Resist Infect Control 2018;7:137.

10. Dieringer TD, Furukawa D, Graber CJ, et al. Inpatient antibiotic utilization in the Veterans' Health Administration during the coronavirus disease 2019 (COVID-19) pandemic. Infect Control Hosp Epidemiol 2021;42:751-753.

11. UK Health Security Agency. English surveillance programme for antimicrobial utilisation and resistance (ESPAUR) report 2020 to 2021 . UK government website. https://www.gov.uk/government/publications/englishsurveillance-programme-antimicrobial-utilisation-and-resistance-espaurreport. Published 2020, page 209. Accessed February 3, 2022.

12. Langford BJ, So M, Raybardhan S, et al. Bacterial coinfection and secondary infection in patients with COVID-19: a living rapid review and metaanalysis. Clin Microbiol Infect 2020;26:1622-1629.

13. Musuuza JS, Watson L, Parmasad V, Putman-Buehler N, Christensen L, Safdar N. Prevalence and outcomes of coinfection and superinfection with SARS-CoV-2 and other pathogens: a systematic review and meta-analysis. PLoS One 2021;16(5):e0251170.

14. Fakih MG, Bufalino A, Sturm L, et al. Coronavirus disease 2019 (COVID19) pandemic, central-line-associated bloodstream infection (CLABSI), and catheter-associated urinary tract infection (CAUTI): the urgent need to refocus on hardwiring prevention efforts. Infect Control Hosp Epidemiol 2022;43:26-31.

15. Winders HR, Bailey $\mathrm{P}, \mathrm{Kohn} \mathrm{J}$, et al. Change in antimicrobial use during COVID-19 pandemic in South Carolina hospitals: a multicenter observational cohort study. Int J Antimicrob Agents 2021;58:106453.

16. Grau S, Hernández S, Echeverría-Esnal D, et al. Antimicrobial consumption among 66 acute-care hospitals in Catalonia: impact of the COVID-19 pandemic. Antibiotics (Basel) 2021;10:943.

17. King LM, Lovegrove MC, Shehab N, et al. Trends in US outpatient antibiotic prescriptions during the coronavirus disease 2019 pandemic. Clin Infect Dis 2021;73:e652-e660.
18. Knight BD, Shurgold J, Smith G, et al. The impact of COVID-19 on community antibiotic use in Canada: an ecological study. Clin Microbiol Infect 2021. doi: 10.1016/j.cmi.2021.10.013.

19. Högberg LD, Vlahović-Palčevski V, Pereira C, Weist K, Monnet DL, ESAC Net study group. Decrease in community antibiotic consumption during the COVID-19 pandemic, EU/EEA, 2020. Eurosurveillance 2021;26:2101020.

20. de Souza Luna LK, Perosa DrAH, Conte DD, et al. Different patterns of influenza A and B detected during early stages of COVID-19 in a university hospital in São Paulo, Brazil. J Infect 2020;81(2):e104-e105.

21. Chow A, Hein AA, Kyaw WM. Unintended consequence: influenza plunges with public health response to COVID-19 in Singapore. $J$ Infect 2020;81(2):e68-e69.

22. Sakamoto $H$, Ishikane $M$, Ueda $P$. Seasonal influenza activity during the SARS-CoV-2 outbreak in Japan. JAMA 2020;323:1969-1971.

23. Kuo SC, Shih SM, Chien LH, Hsiung CA. Collateral benefit of COVID-19 control measures on influenza activity, Taiwan. Emerg Infect Dis 2020;26:1928-1930.

24. Seasonal influenza-annual epidemiological report for 2020-2021. European Centre for Disease Prevention and Control website. https:// www.ecdc.europa.eu/en/publications-data/seasonal-influenza-annualepidemiological-report-2020-2021. Published August 2021. Accessed February 3, 2022.

25. Britton PN, Hu N, Saravanos G, et al. COVID-19 public health measures and respiratory syncytial virus. Lancet Child Adolesc Health 2020;4(11): e42-e43.

26. Brueggemann AB, Jansen van Rensburg MJ, Shaw D, et al. Changes in the incidence of invasive disease due to Streptococcus pneumoniae, Haemophilus influenzae, and Neisseria meningitidis during the COVID-19 pandemic in 26 countries and territories in the Invasive Respiratory Infection Surveillance Initiative: a prospective analysis of surveillance data. Lancet Digital Health 2021;3:e360-e370.

27. Sulis G, Batomen B, Kotwani A, Pai M, Gandra S. Sales of antibiotics and hydroxychloroquine in India during the COVID-19 epidemic: an interrupted time series analysis. PLoS Med 2021;18(7):e1003682.

28. Porter G, Kotwani A, Bhullar L, Joshi J. Over-the-counter sales of antibiotics for human use in India: the challenges and opportunities for regulation. Med Law Int 2021;21:147-173.

29. Belachew SA, Hall L, Erku DA, Selvey LA. No prescription? No problem: drivers of nonprescribed sale of antibiotics among community drug retail outlets in low- and middle-income countries: a systematic review of qualitative studies. BMC Public Health 2021;21:1056.

30. Tomczyk S, Taylor A, Brown A, et al. Impact of the COVID-19 pandemic on the surveillance, prevention, and control of antimicrobial resistance: a global survey. J Antimicrob Chemother 2021;76:3045-3058.

31. Wang Y, Yang J, Qiao F, et al. Compared hand hygiene compliance among healthcare providers before and after the COVID-19 pandemic: a rapid review and meta-analysis: hand hygiene compliance among healthcare providers. Am J Infect Control 2021. doi: 10.1016/ j.ajic.2021.11.030.

32. Israel S, Harpaz K, Radvogin E, et al. Dramatically improved hand hygiene performance rates at time of coronavirus pandemic. Clin Microbiol Infect 2020;26:1566-1568.

33. Makhni S, Umscheid CA, Soo J, et al. Hand hygiene compliance rate during the COVID-19 pandemic. JAMA Intern Med 2021;181:1006-1008.

34. Moore LD, Robbins G, Quinn J, Arbogast JW. The impact of COVID-19 pandemic on hand hygiene performance in hospitals. Am J Infect Control 2021;49:30-33.

35. Huang F, Armando M, Dufau S, Florea O, Brouqui P, Boudjema S. COVID-19 outbreak and healthcare worker behavioural change toward hand hygiene practices. J Hosp Infect 2021;111:27-34.

36. Fulchini R, Kohler P, Kahlert CR, et al. Hand hygiene adherence in relation to influenza season during 6 consecutive years. Am J Infect Control 2018;46:1311-1314.

37. Labarca J, Zambrano A, Niklitschek S, et al. H1N1 pandemic influenza impact on hand hygiene and specific precautions compliance among healthcare workers. J Hosp Infect 2011;79:177-179. 
38. Donà $\mathrm{D}, \mathrm{Di}$ Chiara $\mathrm{C}$, Sharland $\mathrm{M}$. Multidrug-resistant infections in the COVID-19 era: a framework for considering the potential impact. J Hosp Infect 2020;106:198-199.

39. Cantón R, Gijón D, Ruiz-Garbajosa P. Antimicrobial resistance in ICUs: an update in the light of the COVID-19 pandemic. Curr Opin Crit Care 2020;26:433-441.

40. Mulholland RH, Wood R, Stagg HR, et al. Impact of COVID-19 on accident and emergency attendances and emergency and planned hospital admissions in Scotland: an interrupted time-series analysis. $J$ R Soc Med 2020;113:444-453.

41. Writer S. A look at South Africa's new COVID-19 'module' facility, which was built in just months. Business Tech website. https://businesstech.co.za/ news/business/461602/a-look-at-south-africas-new-covid-19-modulefacility-which-was-built-in-just-months/. Published January 2021. Accessed February 3, 2021.

42. Coronavirus: The hospital built in a matter of days. BBC News website. https://www.bbc.com/news/in-pictures-51280586. Published February 2, 2020. Accessed December 13, 2021.

43. Consult QD. COVID-19. How we created a hospital for COVID-19 patients in less than a month. Cleveland Clinic website. https://consultqd. clevelandclinic.org/how-we-created-a-hospital-for-covid-19-patientsin-less-than-a-month/. Published April 2020. Accessed February 3, 2022.

44. Kaier K, Mutters NT, Frank U. Bed occupancy rates and hospital-acquired infections-should beds be kept empty? Clin Microbiol Infect 2012;18:941-945.

45. Castro MG, Ubiergo L, Vicino M, Cuevas G, Argarañá F. An outbreak inside an outbreak: rising incidence of carbapenem-resistant isolates during the COVID-19 pandemic. report from a tertiary care center in Argentina. medRxiv 2021. doi: 10.1101/2021.11.11.21266237.

46. Farfour E, Lecuru M, Dortet L, et al. Carbapenemase-producing Enterobacterales outbreak: another dark side of COVID-19. Am J Infect Control 2020;48:1533-1536.

47. Magnasco L, Mikulska M, Giacobbe DR, et al. Spread of carbapenemresistant gram-negatives and Candida auris during the COVID-19 pandemic in critically ill patients: one step back in antimicrobial stewardship? Microorganisms 2021;9:95.

48. Nori P, Szymczak W, Puius Y, et al. Emerging copathogens: New Delhi metallo-beta-lactamase-producing Enterobacterales infections in New York City COVID-19 patients. Int J Antimicrob Agents 2020;56:106179.

49. Arteaga-Livias K, Pinzas-Acosta K, Perez-Abad L, et al. A multidrugresistant Klebsiella pneumoniae outbreak in a Peruvian hospital: another threat from the COVID-19 pandemic. Infect Control Hosp Epidemiol 2021. doi: 10.1017/ice.2020.1401.

50. Allaw F, Kara Zahreddine N, Ibrahim A, et al. First Candida auris outbreak during a COVID-19 pandemic in a tertiary-care center in Lebanon. Pathogens (Basel, Switzerland) 2021;10:157.

51. de Almeida JN Jr, Brandão IB, Francisco EC, et al. Axillary digital thermometers uplifted a multidrug-susceptible Candida auris outbreak among COVID-19 patients in Brazil. Mycoses 2021;64:1062-1072.

52. Chowdhary A, Sharma A. The lurking scourge of multidrug-resistant Candida auris in times of COVID-19 pandemic. J Glob Antimicrob Resist 2020;22:175-176.

53. Gottesman T, Fedorowsky R, Yerushalmi R, Lellouche J, Nutman A. An outbreak of carbapenem-resistant Acinetobacter baumannii in a COVID19 dedicated hospital. Infect Prevent Pract 2021;3:100113.

54. Prestel C, Anderson E, Forsberg K, et al. Candida auris outbreak in a COVID-19 specialty care unit-Florida, July-August 2020. Morbid Mortal Wkly Rept 2021;70:56-57.

55. Shinohara DR, Dos Santos Saalfeld SM, Martinez HV, et al. Outbreak of endemic carbapenem-resistant Acinetobacter baumannii in a coronavirus disease 2019 (COVID-19)-specific intensive care unit. Infect Control Hosp Epidemiol 2021. doi: 10.1017/ice.2021.98.

56. Villanueva-Lozano H, Treviño-Rangel R de J, González GM, et al. Outbreak of Candida auris infection in a COVID-19 hospital in Mexico. Clin Microbiol Infect 2021;27:813-816.

57. García-Meniño I, Forcelledo L, Rosete Y, García-Prieto E, Escudero D, Fernández J. Spread of OXA-48-producing Klebsiella pneumoniae among
COVID-19-infected patients: the storm after the storm. J Infect Public Health 2020;14:50-52.

58. Perez S. Increase in hospital-acquired carbapenem-resistant Acinetobacter baumannii infection and colonization in an acute care hospital during a surge in COVID-19 admissions-New Jersey, February-July 2020. Morbid Mortal Wkly Rep 2020;69.

59. Sands M, Aunger R. Determinants of hand hygiene compliance among nurses in US hospitals: a formative research study. PLoS One 2020;15: e0230573.

60. Ran L, Chen X, Wang Y, Wu W, Zhang L, Tan X. Risk factors of healthcare workers with coronavirus disease 2019: a retrospective cohort study in a designated hospital of Wuhan in China. Clin Infect Dis 2020;71:22182221.

61. Fuller C, Savage J, Besser S, et al. "The dirty hand in the latex glove": a study of hand hygiene compliance when gloves are worn. Infect Control Hosp Epidemiol 2011;32:1194-1199.

62. Lindberg M, Skytt B, Lindberg M. Continued wearing of gloves: a risk behaviour in patient care. Infect Prevent Pract 2020;2(4):100091.

63. Tiri B, Sensi E, Marsiliani V, et al. Antimicrobial stewardship program, COVID-19, and infection control: spread of carbapenem-resistant Klebsiella pneumoniae colonization in ICU COVID-19 patients. What did not work? J Clin Microbiol 2020;9:2744.

64. Burki T. Global shortage of personal protective equipment. Lancet Infect Dis 2020;20:785-786.

65. Phua J, Weng L, Ling L, et al. Intensive care management of coronavirus disease 2019 (COVID-19): challenges and recommendations. Lancet Respir Med 2020;8:506-517.

66. Ranney ML, Griffeth V, Jha AK. Critical supply shortages-the need for ventilators and personal protective equipment during the COVID-19 pandemic. N Engl J Med 2020;382(18):e41.

67. Ford S. Infection control concerns spark new advice on PPE use during the COVID-19 crisis. Nursing Times website. https://www.nursingtimes.net/ news/policies-and-guidance/infection-control-concerns-spark-new-adviceon-ppe-use-during-covid-19-crisis-21-05-2020/. Published May 2020. Accessed February 3, 2022.

68. Nguyen LH, Drew DA, Graham MS, et al. Risk of COVID-19 among frontline healthcare workers and the general community: a prospective cohort study. Lancet Public Health 2020;5:e475-e483.

69. Søvold LE, Naslund JA, Kousoulis AA, et al. Prioritizing the mental health and well-being of healthcare workers: an urgent global public health priority. Front Public Health 2021;9:514.

70. Fujita K, Kashihara E, Kanai O, et al. Increasing burden of nursing care on the treatment of COVID-19 patients in the aging society: analyses during the first to the third wave of pandemic in Kyoto City, Japan. Front Med 2021;8:2244.

71. Risk Factors for the Transmission of methicillin-resistant Staphylococcus aureus in an adult intensive care unit: fitting a model to the data. J Infect Dis 2002;185:481-488.

72. Stevens MP, Patel PK, Nori P. Involving antimicrobial stewardship programs in COVID-19 response efforts: All hands on deck. Infect Control Hosp Epidemiol 2020;41:744-745.

73. Bokhary H, Pangesti KNA, Rashid H, Abd El Ghany M, Hill-Cawthorne GA. Travel-related antimicrobial resistance: a systematic review. Trop Med 2021;6:11.

74. Rolain JM, Parola P, Cornaglia G. New Delhi metallo-beta-lactamase (NDM-1): towards a new pandemia? Clin Microbiol Infect 2010;16:1699-1701.

75. Fulchini R, Albrich WC, Kronenberg A, et al. Antibiotic-resistant pathogens in different patient settings and identification of surveillance gaps in Switzerland-a systematic review. Epidemiol Infect 2019;147:e259.

76. Arcilla MS, Hattem JM van, Haverkate MR, et al. Import and spread of extended-spectrum $\beta$-lactamase-producing Enterobacteriaceae by international travellers (COMBAT study): a prospective, multicentre cohort study. Lancet Infect Dis 2017;17:78-85.

77. D'Souza AW, Boolchandani M, Patel S, et al. Destination shapes antibiotic resistance gene acquisitions, abundance increases, and diversity changes in Dutch travelers. Genome Med 2021;13:79. 
78. Kohler PP, Melano RG, Patel SN, et al. Emergence of carbapenemase-producing Enterobacteriaceae, south-central Ontario, Canada. Emerg Infect Dis 2018;24:1674-1682.

79. Nordmann P, Poirel L. The difficult-to-control spread of carbapenemase producers among Enterobacteriaceae worldwide. Clin Microbiol Infect 2014;20:821-830.

80. Carriage of resistant microorganisms in repatriates from foreign hospitals to The Netherlands. Clin Microbiol Infect 2004;10:972-979.

81. Lemmenmeier E, Kohler P, Bruderer T, Goldenberger D, Kleger GR, Schlegel M. First documented outbreak of KPC-2-producing Klebsiella pneumoniae in Switzerland: infection control measures and clinical management. Infection 2014;42:529-534.

82. Zapor MJ, Erwin D, Erowele G, Wortmann G. Emergence of multidrug resistance in bacteria and impact on antibiotic expenditure at a major army medical center caring for soldiers wounded in Iraq and Afghanistan. Infect Control Hosp Epidemiol 2008;29:661-663.

83. Jones A, Morgan D, Walsh A, et al. Importation of multidrug-resistant Acinetobacter spp infections with casualties from Iraq. Lancet Infect Dis 2006;6:317-318.

84. Kommenda N. How is the coronavirus affecting global air traffic? The Guardian website. https://www.theguardian.com/world/ng-interactive/ 2020/apr/03/how-is-the-coronavirus-affecting-global-air-traffic. Published April 2020. Accessed February 3, 2022.

85. Rega Annual Report 2020. Rega Research website. https://www.rega.ch/ fileadmin/seiteninhalt/4_Aktuell/2_Publikationen/2_Jahresbericht/ Rega_Jahresbericht_2020_en.pdf. Page 40. Published 2021. Accessed February 3, 2022.

86. Murray AK. The novel coronavirus COVID-19 outbreak: global implications for antimicrobial resistance. Front Microbiol 2020;11:1020.

87. COVID-19 community mobility report. Google website. https://www. google.com/covid19/mobility/. Updated daily. Accessed February 3, 2022.

88. Kishore K, Jaswal V, Verma M, Koushal V. Exploring the utility of google mobility data during the COVID-19 pandemic in India: digital epidemiological analysis. J Med Internet Res Public Health Surveill 2021;7:e29957.

89. Conceição T, Diamantino F, Coelho C, de Lencastre H, Aires-de-Sousa M. Contamination of public buses with MRSA in Lisbon, Portugal: a possible transmission route of major MRSA clones within the community. PLoS One 2013;8:e77812.

90. Kahsay AG, Asgedom SW, Weldetinsaa HL. Enteric bacteria, methicillinresistant $S$. aureus, and antimicrobial susceptibility patterns from buses surfaces in Mekelle city, Tigray, Ethiopia. BMC Res Notes 2019;12:337.

91. Otter J a., French G 1. Bacterial contamination on touch surfaces in the public transport system and in public areas of a hospital in London. Lett Appl Microbiol 2009;49:803-805.

92. Mendes Â, Martins da Costa P, Rego D, et al. Contamination of public transports by Staphylococcus aureus and its carriage by biomedical students: point-prevalence, related risk factors and molecular characterization of methicillin-resistant strains. Public Health 2015;129:1125-1131.

93. Stepanović S, Cirković I, Djukić S, Vuković D, Svabić-Vlahović M. Public transport as a reservoir of methicillin-resistant staphylococci. Lett Appl Microbiol 2008;47:339-341.

94. Annual surveillance reports on antimicrobial resistance. European Centre for Disease Prevention and Control website. https://www.ecdc.europa.eu/en/ antimicrobial-resistance/surveillance-and-disease-data/report. Published November 2020. Accessed February 3, 2022.

95. Epidemiological alert: emergence and increase of new combinations of carbapenemases in Enterobacterales in Latin America and the Caribbean, 22 October 2021. Pan American Health Organization website. https://www.paho.org/en/documents/epidemiological-alert-emergenceand-increase-new-combinations-carbapenemases. Published October 2021. Accessed February 3, 2022.

96. Incidence of carbapenemase-producing Enterobacterales (CPE) in Switzerland, 2020-2021. Swiss Centre for Antibiotic Resistance (ANRESIS) website. http://www.anresis.ch/wp-content/uploads/2021/ 08/CPE_Gasser_Poster_SSI_2021_08_25.pdf. Published August 2021. Accessed February 3, 2022.
97. Hirabayashi A, Kajihara T, Yahara K, Shibayama K, Sugai M. Impact of the COVID-19 pandemic on the surveillance of antimicrobial resistance. $J$ Hosp Infect 2021;117:147-156.

98. Rawson TM, Moore LSP, Castro-Sanchez E, et al. COVID-19 and the potential long-term impact on antimicrobial resistance. J Antimicrob Chemother 2020;75:1681-1684.

99. Huttner BD, Catho G, Pano-Pardo JR, Pulcini C, Schouten J. COVID-19: don't neglect antimicrobial stewardship principles! Clin Microbiol Infect 2020;26:808-810.

100. Macera M, Onorato L, Calò F, et al. The impact of the SARS-Cov2 pandemic on a persuasive educational antimicrobial stewardship program in a university hospital in southern Italy: a pre-post study. Antibiotics 2021;10:1405

101. Mazdeyasna H, Nori P, Patel P, et al. Antimicrobial stewardship at the core of COVID-19 response efforts: implications for sustaining and building programs. Curr Infect Dis Rep 2020;22(9):23.

102. Stevens RW, Estes L, Rivera C. Practical implementation of COVID-19 patient flags into an antimicrobial stewardship program's prospective review. Infect Control Hosp Epidemiol 2020;41:1108-1110.

103. Kubin CJ, Loo AS, Cheng J, et al. Antimicrobial stewardship perspectives from a New York City hospital during the COVID-19 pandemic: challenges and opportunities. Am J Health Sys Pharm 2021;78:743-750.

104. Kondilis E, Tarantilis F, Benos A. Essential public healthcare services utilization and excess non-COVID-19 mortality in Greece. Public Health 2021;198:85-88.

105. Schmidt AL, Bakouny Z, Bhalla S, et al. Cancer care disparities during the COVID-19 pandemic: COVID-19 and cancer outcomes study. Cancer Cell 2020;38:769-770.

106. Roy CM, Bollman EB, Carson LM, Northrop AJ, Jackson EF, Moresky RT. Assessing the indirect effects of COVID-19 on healthcare delivery, utilization and health outcomes: a scoping review. Eur J Public Health 2021;31:634-640.

107. Rawson TM, Ming D, Ahmad R, Moore LSP, Holmes AH. Antimicrobial use, drug-resistant infections and COVID-19. Nat Rev Microbiol 2020;18:409-410.

108. Russell AD. Mechanisms of antimicrobial action of antiseptics and disinfectants: an increasingly important area of investigation. J Antimicrob Chemother 2002;49:597-599.

109. Dewey HM, Jones JM, Keating MR, Budhathoki-Uprety J. Increased use of disinfectants during the COVID-19 pandemic and its potential impacts on health and safety. ACS Chem Health Saf 2022;29:27-38.

110. Dwyer C. "A monumental undertaking": NYC subway to disinfect every train each night. National Public Radio website. https:/www.npr.org/ sections/coronavirus-live-updates/2020/05/02/849589416/a-monumentalundertaking-nyc-subway-to-disinfect-every-train-each-night. Published May 2, 2020. Accessed December 21, 2021.

111. Ansari S, Hays JP, Kemp A, et al. The potential impact of the COVID-19 pandemic on global antimicrobial and biocide resistance: an AMR Insights global perspective. JAC Antimicrob Resist 2021;3(2):dlab038.

112. Bock LJ. Bacterial biocide resistance: a new scourge of the infectious disease world? Arch Dis Child 2019;104:1029-1033.

113. Maillard JY. Resistance of bacteria to biocides. Microbiol Spect 2018. doi: 10.1128/microbiolspec.ARBA-0006-2017.

114. Robben C, Fister S, Witte AK, Schoder D, Rossmanith P, Mester P. Induction of the viable but nonculturable state in bacterial pathogens by household cleaners and inorganic salts. Sci Rep 2018;8:15132.

115. Amuasi JH, Walzer C, Heymann D, et al. Calling for a COVID-19 One Health Research Coalition. Lancet 2020;395:1543-1544.

116. Peyre M, Vourc'h G, Lefrançois T, Martin-Prevel Y, Soussana JF, Roche B. PREZODE: preventing zoonotic disease emergence. Lancet 2021;397:792-793.

117. Venkatesan P. Collaborate to stop antimicrobial resistance-for the sake of the planet. Lancet Microbe 2021;2(10):e497.

118. Chandir S, Arif Siddiqi D, Mehmood M, et al. Impact of COVID-19 pandemic response on uptake of routine immunizations in Sindh, Pakistan: an analysis of provincial electronic immunization registry data. Vaccine 2020;38:7146-7155. 
119. Alsuhaibani M, Alaqeel A. Impact of the COVID-19 pandemic on routine childhood immunization in Saudi Arabia. Vaccines (Basel) 2020;8:581.

120. Santoli JM. Effects of the COVID-19 Pandemic on routine pediatric vaccine ordering and administration-United States, 2020. Morbid Mortal Wkly Rep 2020;69.

121. Patel Murthy B, Zell E, Kirtland K, et al. Impact of the COVID-19 pandemic on administration of selected routine childhood and adolescent vaccinations-10 US jurisdictions, March-September 2020. Morbid Mortal Wkly Rep 2021;70:840-845.

122. Rebuilding resilient health systems for Europe. Lancet Reg Health Eur 2021;9:100238
123. Maher B, Van Noorden R. How the COVID pandemic is changing global science collaborations. Nature 2021;594:316-319.

124. Cars O, Chandy SJ, Mpundu M, Peralta AQ, Zorzet A, So AD. Resetting the agenda for antibiotic resistance through a health systems perspective. Lancet Glob Health 2021;9:e1022-e1027.

125. Veepanattu P, Singh S, Mendelson M, et al. Building resilient and responsive research collaborations to tackle antimicrobial resistance-lessons learnt from India, South Africa, and UK. Int J Infect Dis 2020;100:278-282.

126. Pokharel S, Raut S, Adhikari B. Tackling antimicrobial resistance in lowincome and middle-income countries. BMJ Global Health 2019;4: e002104. 